\title{
A next-generation microarray further reveals stage-enriched gene expression pattern in the blood fluke Schistosoma japonicum
}

Pengfei Cai ${ }^{1,2^{*}+}$, Shuai Liu ${ }^{1+}$, Xianyu Piao ${ }^{1}$, Nan Hou ${ }^{1}$, Hong You ${ }^{2}$, Donald P. McManus ${ }^{2^{*}}$ and Qijun Chen ${ }^{1,3^{*}}$

\begin{abstract}
Background: Schistosomiasis is caused by infection with blood flukes of the genus Schistosoma, and ranks, in terms of disability-adjusted life years (DALYs), as the third most important neglected tropical disease. Schistosomes have several discrete life stages involving dramatic morphological changes during their development, which require subtle gene expression modulations to complete the complex life-cycle.

Results: In the current study, we employed a second generation schistosome DNA chip printed with the most comprehensive probe array for studying the Schistosoma japonicum transcriptome, to explore stage-associated gene expression in different developmental phases of S. japonicum. A total of 328, 95, 268 and 532 mRNA transcripts were enriched in cercariae, hepatic schistosomula, adult worms and eggs, respectively. In general, genes associated with transcriptional regulation, cell signalling and motor activity were readily expressed in cercariae; the expression of genes involved in neuronal activities, apoptosis and renewal was modestly upregulated in hepatic schistosomula; transcripts involved in egg production, nutrition metabolism and glycosylation were enriched in adult worms; while genes involved in cell division, microtubule-associated mobility, and host-parasite interplay were relatively highly expressed in eggs.

Conclusions: The study further highlights the expressional features of stage-associated genes in schistosomes with high accuracy. The results provide a better perspective of the biological characteristics among different developmental stages, which may open new avenues for identification of novel vaccine candidates and the development of novel control interventions against schistosomiasis.
\end{abstract}

Keywords: Schistosoma japonicum, Microarray, Gene profiling, Stage-enriched expression, Developmental biology

\section{Background}

Schistosomiasis, a debilitating and chronic disease caused by infection with blood flukes (digenetic trematodes) of the genus Schistosoma, remains one of the most significant parasitic diseases worldwide, afflicting more than 230 million people, with about 800 million exposed to the risk of the infection $[1,2]$. Schistosomiasis caused about 3.31

\footnotetext{
* Correspondence: Pengfei.Cai@qimrberghofer.edu.au;

Don.McManus@qimrberghofer.edu.au; qijun.chen@ipbcams.ac.cn

${ }^{\dagger}$ Equal contributors

${ }^{1} \mathrm{MOH}$ Key Laboratory of Systems Biology of Pathogens, Institute of Pathogen Biology, Chinese Academy of Medical Sciences \& Peking Union Medical College, Beijing, People's Republic of China

${ }^{2}$ Molecular Parasitology Laboratory, QIMR Berghofer Medical Research

Institute, Queensland, Australia

Full list of author information is available at the end of the article
}

million DALYs in 2010, exceeded only by intestinal nematode infections and leishmaniasis, in the list of global neglected tropical diseases [3]. Schistosoma mansoni, S. haematobium and S. japonicum are the three main species of clinical relevance. Currently, there are no practical anti-schistosome vaccines available. The repeated use of a single effective drug, praziquantel, is required for schistosomiasis treatment, while a variety of morbidity management strategies have been adopted for control of the disease $[4,5]$.

The schistosome life-cycle involves an aquatic snail as an intermediate host and a mammal as definitive host [6]. Schistosome cercariae are shed from infected snails under a light stimulus and are released into water 
resources. The free-swimming cercariae infect a mammalian host by skin contact. After skin penetration, the larvae lose their tails and transform into schistosomula. Once entering into capillaries or lymphatic vessels, they are carried to the heart and lungs within 3-5 days depending on the species. The lung-stage schistosomula continue migration to the hepatic portal system at about 14-days post-infection, where the juveniles pair up and become sexually mature. Then the schistosomes in copula migrate to the mesenteric veins ( $S$. mansoni and $S$. japonicum) or the pelvic venous plexus (S. haematobium), where the female worms lay eggs intravascularly, with varied patency periods among the species. Some eggs are lodged in tissues causing disease whereas others enter the intestine or bladder and are excreted from the host. The mature eggs hatch under favourable conditions to release miracidia which penetrate a snail host and develop asexually into mother and then daughter sporocysts, within which cercariae are produced, which are then released from the snail and continue the life-cycle.

The availability of schistosome transcriptome $[7,8]$ and genome sequences [9-11] for the three major Schistosoma spp., provides an invaluable resource to profile gene expression across different developmental stages and between the sexes. In this respect, high-throughput technologies, such as microarrays [12-18], serial analysis of gene expression (SAGE) [19-21], digital gene expression (DGE) [22], and, more recently, RNAseq [23, 24] have been employed in the analysis of gene profiling in schistosomes. These pioneering investigations have provided unique information on developmental-enriched, gender-biased, tissue-specific, strain-specific and hostassociated gene expression features within schistosomes $[12,14,25-28]$, revealing critical insight on the biology of these parasites. With respect to using microarray platforms, the interpretation of microarray experiment depends on the quality of genetic information contained in the collection of DNA templates employed for probe design. The first-generation of schistosome cDNA chips were printed based on EST transcripts, so that the data obtained from these chip experiments resulted in a poor interpretation due to the problems in annotating these ESTs [12-14]. We considered it essential to generate a second generation DNA microarray with a well-curated probe design, based on both transcriptomic and genomic sequences, in order to increase our understanding of schistosome biology.

We have constructed a second generation schistosome DNA chip printed with the most comprehensive coverage of probes, designed based on S. japonicum and $S$. mansoni genomic and transcriptomic sequences for transcriptomic studies [29-31]. Here, we have identified stage-enriched transcripts in cercariae, hepatic schistosomula, adult worms and eggs using this next-generation
DNA microarray. This study presents a comprehensive view of the expression features of stage-enriched genes for four developmental phases of S. japonicum, and provides novel insights on schistosome developmental biology.

\section{Methods}

Parasite materials

Schistosoma japonicum-infected snails (Oncomelania hupensis) were purchased from Hunan Institute of Parasitic Diseases, Yueyang, China. Cercariae were shed from these snails under light stimulation and were collected. Hepatic schistosomula at 14 days post-infection (p.i.) were perfused from $S$. japonicum-infected New Zealand rabbits via the vascular system. Mixed adult worms were perfused from $S$. japonicum-infected rabbits at 6 weeks p.i. Schistosome eggs were purified from liver tissues of infected rabbits (6 weeks p.i.) by enzyme digestion [32]. All parasite samples (except eggs) were soaked in RNAlater (Ambion, CA, USA), and stored at $-80{ }^{\circ} \mathrm{C}$ until total RNA extraction. Total RNA from eggs was isolated immediately after purification.

\section{Total RNA isolation}

Total RNA samples were isolated from S. japonicum cercariae, hepatic schistosomula, adult worms and eggs using RNeasy Mini kits (QIAGEN, GmbH, Hilden, Germany) according to the manufacturer's instructions. Potential contaminating genomic DNA was removed from RNA samples using a Turbo DNA-free kit (Ambion, CA, USA). The quantity of RNA in each sample was assessed by a NanoDropND-1000 spectrophotometer (NanoDrop Technologies, Wilmington, DE). The integrity of total RNA in each sample was checked by denaturing agarose gel electrophoresis (Additional file 1: Figure S1).

\section{Microarray construction and hybridization and subsequent data analysis}

A schistosome genome-wide microarray was employed for profiling the gene expression in S. japonicum cercariae, hepatic schistosomula, adult worms and eggs. The details regarding the design and construction of the microarray, the hybridization method, and feature extraction have been reported [29-33]. For each target sequence, 3 or 4 pairs of complementary oligonucleotide probes (forward and reverse, 60-mer) were designed (in total 145,000 probes). Probes with random sequences were printed as negative controls (background signal), while eight spike-RNA probes from the intergenic sequence of yeast were used as hybridization controls. Microarrays were printed in a $12 \times 135 \mathrm{~K}$ feature format (Roche NimbleGen) representing 41,982 features. cDNA was labelled with a fluorescent dye (Cy3-dCTP) using a cRNA Amplification and Labelling Kit (CapitalBio, Beijing, China) [34]. Hybridization was performed using 
three biological replicates for all samples by CapitalBio, Beijing, China. Procedures for array hybridization, washing, scanning, and data acquisition were performed according to the NimbleGen Arrays User's Guide. The arrays were scanned using a MS200 scanner (NimbleGen Systems) at $2-\mu \mathrm{m}$ resolution, and NimbleScan software (NimbleGen) was employed to extract fluorescent intensity raw data from the scanned images. Normalized gene expression data were generated using the Robust Multichip Average (RMA) algorithm [35, 36]. Outlier probes were identified and their contribution was reduced at the reported gene expression level [36]. The expression value of a gene is a weighted average of all forward or reverse probe sets when both background correction and quantile normalization are performed.

\section{Bioinformatics analysis on stage-enriched mRNA and EST transcripts}

mRNA and EST transcripts highly enriched in cercariae, hepatic schistosomula, adult worms and eggs of S. japonicum were retrieved from the NCBI database (http:// www.ncbi.nlm.nih.gov/sites/batchentrez) based on foldchange $(\mathrm{FC}=$ the mean intensity/the median of the mean intensity values of the four developmental stages) values. ( $\mathrm{FC} \geq 2$ for both forward and reverse probe sets, and three biological replicates were used for each stage). Student's $t$ test was used to determine differentially expressed genes between one particular stage and any of the other three stages $[28,30](P<0.05)$. Heat maps were constructed based on the transformed $\log _{2} \mathrm{FC}$ values (forward probe sets) using HemI 1.0 software [37]. Blast2GO was used to annotate the four gene sets functionally [38]. A comprehensive re-annotation was performed against these gene sets using the BLASTx algorithm, with the annotation of S. mansoni, S. haematobium and Clonorchis sinensis homologues as a reference. For possible improved annotation, potential conserved protein domains were searched against genes annotated as hypothetical protein or unknown in the NCBI CDD database (v3.14) [39].

\section{Quantitative real-time PCR}

A total of 20 stage-enriched genes were selected for validation using qRT-PCR as described [29]. One microgram total RNA samples were reverse transcribed into firststrand cDNA using a SuperScript III Reverse Transcriptase Kit (Invitrogen, Carlsbad, CA, USA) with oligo (dT) 15 primer. The cDNA products were diluted 20 -fold with nuclease-free water before undertaking the qPCR. Each $25 \mu \mathrm{l} \mathrm{PCR}$ reaction contained $12.5 \mu \mathrm{l}$ of $2 \times$ Brilliant II SYBR Green QPCR Master Mix (Agilent, USA), $1 \mu \mathrm{l}$ cDNA, $1 \mu \mathrm{l}$ of the forward and reverse primer pair (Additional file 2: Table S1), and $10.5 \mu \mathrm{l}$ of sterile water. PCR cycling conditions were as follows: $95{ }^{\circ} \mathrm{C}$ for $10 \mathrm{~min}$, followed by 40 cycles of $30 \mathrm{~s}$ denaturation at
$95{ }^{\circ} \mathrm{C}$ and $1 \mathrm{~min}$ annealing and extension at $60{ }^{\circ} \mathrm{C}$. A dissociation step $\left(95{ }^{\circ} \mathrm{C}\right.$ for $15 \mathrm{~s}, 60{ }^{\circ} \mathrm{C}$ for $1 \mathrm{~min}, 95{ }^{\circ} \mathrm{C}$ for $15 \mathrm{~s}$ and $60{ }^{\circ} \mathrm{C}$ for $15 \mathrm{~s}$ ) was performed to confirm the amplification specificity for each gene. $26 \mathrm{~S}$ proteasome non-ATPase regulatory subunit 4 (PSMD4) $[29,40]$ was employed as a house-keeping gene in the assays. PCR reactions were performed in technical triplicates on the 7300 Real-Time PCR system (Applied Biosystems). The relative expression level of each gene was analysed using SDS 1.4 software (Applied Biosystems). Correlations between the microarray and $\mathrm{qPCR}$ results for 20 stage-enriched genes were analysed with the Spearman's rho.

\section{Results and discussion}

Global view of stage-enriched mRNA transcripts in $S$. japonicum

By employing a microarray with the most comprehensive probe coverage design to date, signal intensities from 3571, 1014, 1728 and 3381 sequences were found to be enriched ( $F C$ of mean of intensity value to the median of the mean of intensity values of the four stages $\geq 2$ ) in cercariae, hepatic schistosomula, adult worms and eggs, respectively. Based on the initial screening, we further retrieved a total of 1768 potential mRNA transcripts and 470 expressed sequence tags (ESTs) associated with developmental stages from the NCBI database (Additional file 3: Table S2). The gene collection was further filtered by requiring FC values from both forward and reverse probe sets $\geq 2$. This filtration finally retained $328,95,268$ and 532 mRNA transcripts highly enriched in cercariae, hepatic schistosomula, adult worms and eggs, respectively (Additional files 4, 5, 6 and 7: Tables S3-S6), which contrasted with 128, 31, 83 and 84 ESTs, respectively, highly enriched in these four stages (Additional files 8, 9, 10 and 11: Tables S7-S10). However, the percentage of genes that were annotated as hypothetical protein or unknown $(23.57 \%$ in the mRNA data in contrast to $69.01 \%$ in the EST data), highlights the utility of the second generation S. japonicum DNA chip in profiling gene expression in this parasite.

We observed that more mRNA transcripts were enriched in the egg stage than in the other stages, with a stronger biased expression (higher FC value) (Figs 1 and 2a-d). For example, 46.1\% egg-enriched mRNA transcripts showed a strong biased expression $(\mathrm{FC}>10)$; this number decreased to $22.0 \%$ in adult worms, and further dropped to only 3.0 and $1.1 \%$ in cercariae and hepatic schistosomula, respectively. A similar tendency was observed when analysing the stage-enriched EST transcripts (Additional file 12: Figure S2). In regards to fluorescence intensity, 13.4, 8.42, 25.0 and $27.5 \%$ mRNA transcripts enriched in cercariae, hepatic schistosomula, 


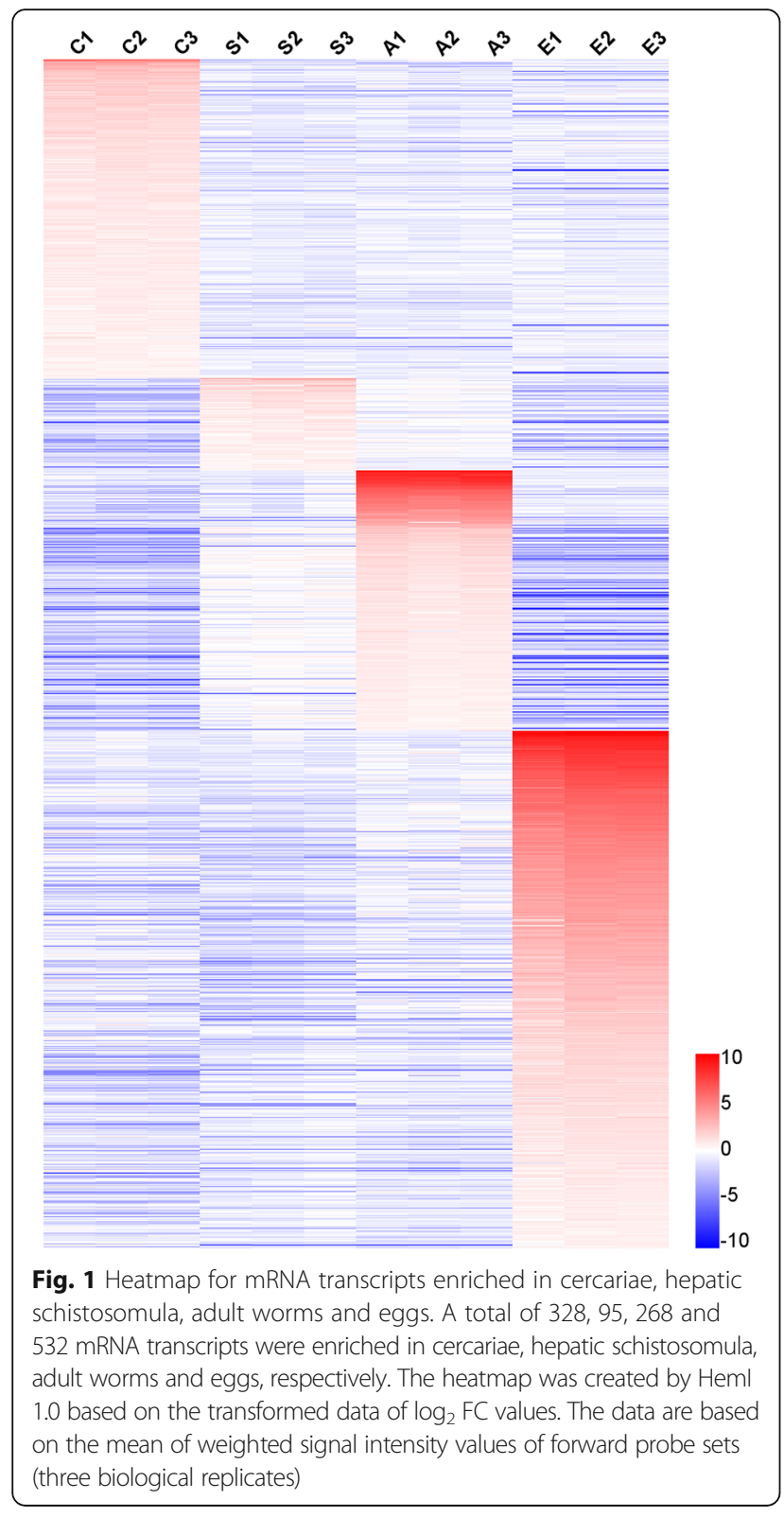

adult worms and eggs, respectively showed an average intensity value $>10,000$ (Fig. 2e-h).

\section{Comparing the results with previous transcriptome data}

A complete and accurate comparison of the results obtained in the current study with data from previous reports is hindered due to the following reasons. Firstly, the annotation of stage-enriched genes was not ideal in previous reports due to the fact that EST sequences were used for probe design coupled with less sequence homology information from other trematode species being available. Secondly, the annotation for the same gene may not have been unique. Thirdly, the screening criteria for stage-enriched genes may have varied among different studies. Nevertheless, we compared our data with these from previous Schistosoma transcriptome data [7, 13, 14, 23, 28] by manual checking. Globally, about 4.57, 10.07 and $12.97 \%$ genes enriched in cercariae, adult worms and eggs, respectively, were reported in previous studies (Additional files 4, 5 and 7: Tables S3, S4, S6). With respect to hepatic schistosomula (14 days p.i.), to our knowledge the only other relevant investigation on this particular stage was carried out on S. mansoni by Fitzpatrick et al. [28], but no enriched gene clustering was evident in that study. This was probably due to the fact a large number (15) of distinct stages were analysed [28], and this has made comparison with our data for hepatic schistosomula difficult.

\section{qPCR validation of the expression pattern of stage- enriched genes}

A subset of 20 representative stage-enriched genes was selected for qRT-PCR validation (Figs 3 and 4a-d). Most genes were associated with important biological functions in each of the parasite forms. The expression of these genes at the four developmental stages validated by qRTPCR analysis significantly correlated with the results obtained by microarray: for cercariae-enriched genes selected, $r_{(30)}=0.8959, P<0.0001$ (Fig. 4e); for hepatic schistosomula-enriched genes selected, $r_{(30)}=0.7375$, $P<0.0001$ (Fig. 4f); for adult-enriched genes selected, $r_{(20)}=0.9082, \quad P<0.0001$ (Fig. 4g); for egg-enriched genes selected, $r_{(21)}=0.8983, P<0.0001$ (Fig. 4 h).

\section{Putative functions predicted by GO analysis}

We analysed the potential biological functions of the stage-enriched genes in S. japonicum using GO classification [41] (Fig. 5, Additional files 13, 14, 15 and 16: Tables S11-S14). Of the biological process categories, the most highly enriched GO terms were organic substance metabolic process, single-organism cellular process, primary metabolic process and cellular metabolic process for cercariae, adult worms and eggs; the first three of these GO terms and regulation of cellular process were the most highly enriched GO terms for hepatic schistosomula. The percentages of genes involved in regulation of cellular process, cellular response to stimulus, and single organism signaling were higher in cercariae and schistosomula than those in adults and eggs. Of the molecular function categories, the percentages of genes involved in ion, heterocyclic compound and organic cyclic compound, small molecule and carbohydrate derivative binding were higher in cercariae and schistosomula than in adults and eggs. A higher percentage of genes related to protein binding, signaling receptor activity and receptor activity were observed in schistosomula, while the GO term extracellular matrix structural constituent was only evident for this stage. In addition, a higher percentage of genes involved in hydrolase activity were assigned to adult worms. In the 


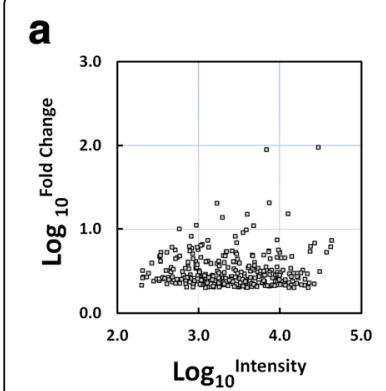

e

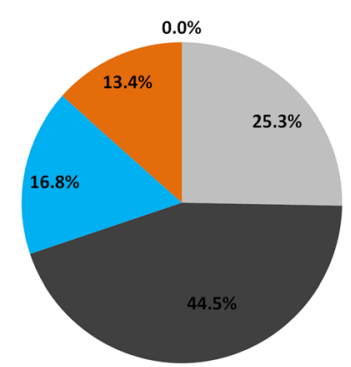

b

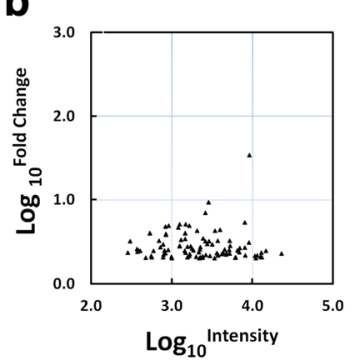

f

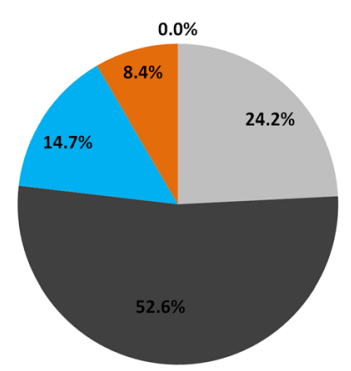

C

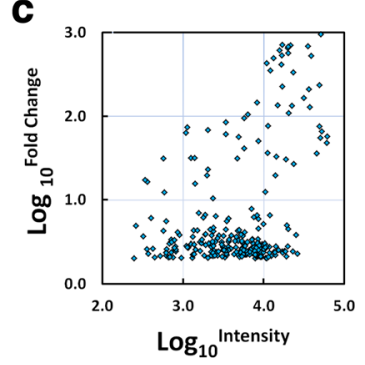

g

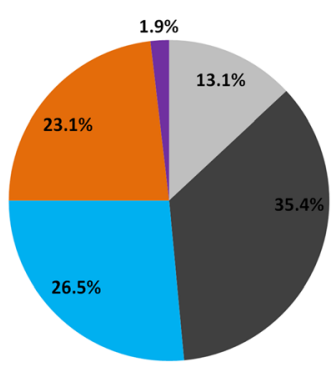

d

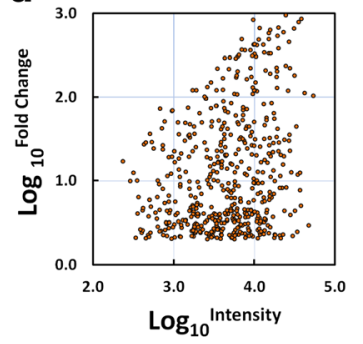

h

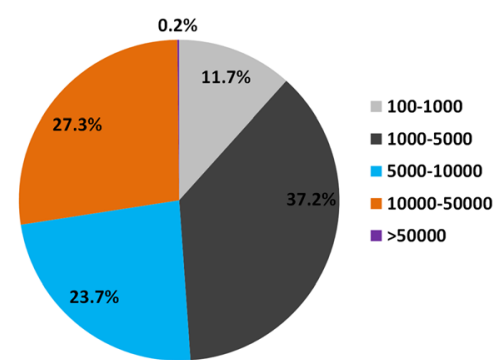

Fig. 2 Bias ratio and signal intensity analysis of stage-associated genes. Scatter plot showing the distribution of the bias ratio and fluorescence intensity for mRNA transcripts enriched in cercariae (a), hepatic schistosomula (b), adult worms (c), and eggs (d). The y-axis corresponds to bias ratios (FC value) and the $x$-axis corresponds to the fluorescence intensities, both of which are $\log _{10}$-transformed. Pie diagrams representing the percentage of stage-enriched mRNA transcripts in cercariae (e), hepatic schistosomula (f), adult worms (g), and eggs (h) showed by different fluorescence intensities

cellular component categories, gene products localised to intracellular, intracellular part and intracellular organelle were more abundant in cercariae, while gene products localised to intrinsic component of membrane were more enriched in the other three stages. Further, genes with GO terms of protein complex, cell periphery, plasma membrane, plasma membrane part and proteinaceous extracellular matrix were relatively enriched in hepatic schistosomula. In addition, the GO term cilium was present only in the egg stage.

\section{The top 25 genes enriched in S. japonicum cercariae,} hepatic schistosomula, adult worms and eggs

The top 25 highly stage-associated genes in cercariae, hepatic schistosomula, adult worms and eggs were analysed (Table 1). Collectively, the upregulated expression of these genes in cercariae indicates that signal transduction (ribosomal protein S6 kinase beta-2 [42]), vesicular trafficking (calcium-dependent secretion activator [43] and small GTPase Rab-protein 11 [44]) and energy metabolism (AMP deaminase [45] and 5'-AMP-activated protein kinase [46]) and transcriptional regulation (krueppel-like factor 11, homeobox protein SMOX-1, and retinoid X receptor RXR-2) are active processes in this stage.

The over-expression of the top 25 genes in hepatic schistosomula appears to reflect a diversity of physiological activities, including transcriptional (homeobox protein engrailed-like SMOX-2 [47, 48], serum and glucocorticoid-regulated kinase 1 (SGK1) [49] and nuclear receptor subfamily 4 group A $[50,51])$ and neuronal (protocadherin FAT4 [52], Aromatic-L-amino-acid decarboxylase [53] and delphilin [54]) activities, together with tegumental integrity (annexin A3 $[55,56]$ ), skeletal morphogenesis (protocadherin FAT4 [57]) and endosome-to-Golgi retrieval (vacuolar protein sortingassociated protein 29 [58]).

In mixed adult worms, genes encoding a number of trematode eggshell synthesis (TES) domain-containing proteins, DDR48 stress proteins, an asparagine-rich antigen Pfa35-2, two distinct tyrosinase homologues, cadherin, female-specific protein 800 and a prostatic sperminebinding protein are listed in the top 25 enriched mRNA transcripts (Table 1). Most of these genes are femalebiased expressed genes [59] with potential molecular functions in egg production [60].

In the egg stage, genes encoding a glutenin high molecular weight subunit DX5, egg protein CP1531, two histidine-rich glycoproteins, three ribonucleases, two tetraspanins, three venom allergen-like (VAL) proteins and cell wall integrity and stress response component 1 are present in the top 25 upregulated mRNA transcripts (Table 1). Notably, it has been shown that T2 ribonuclease omega-1 in soluble egg antigen is a major Th2 polarizing component, which is capable of regulating inflammasome 


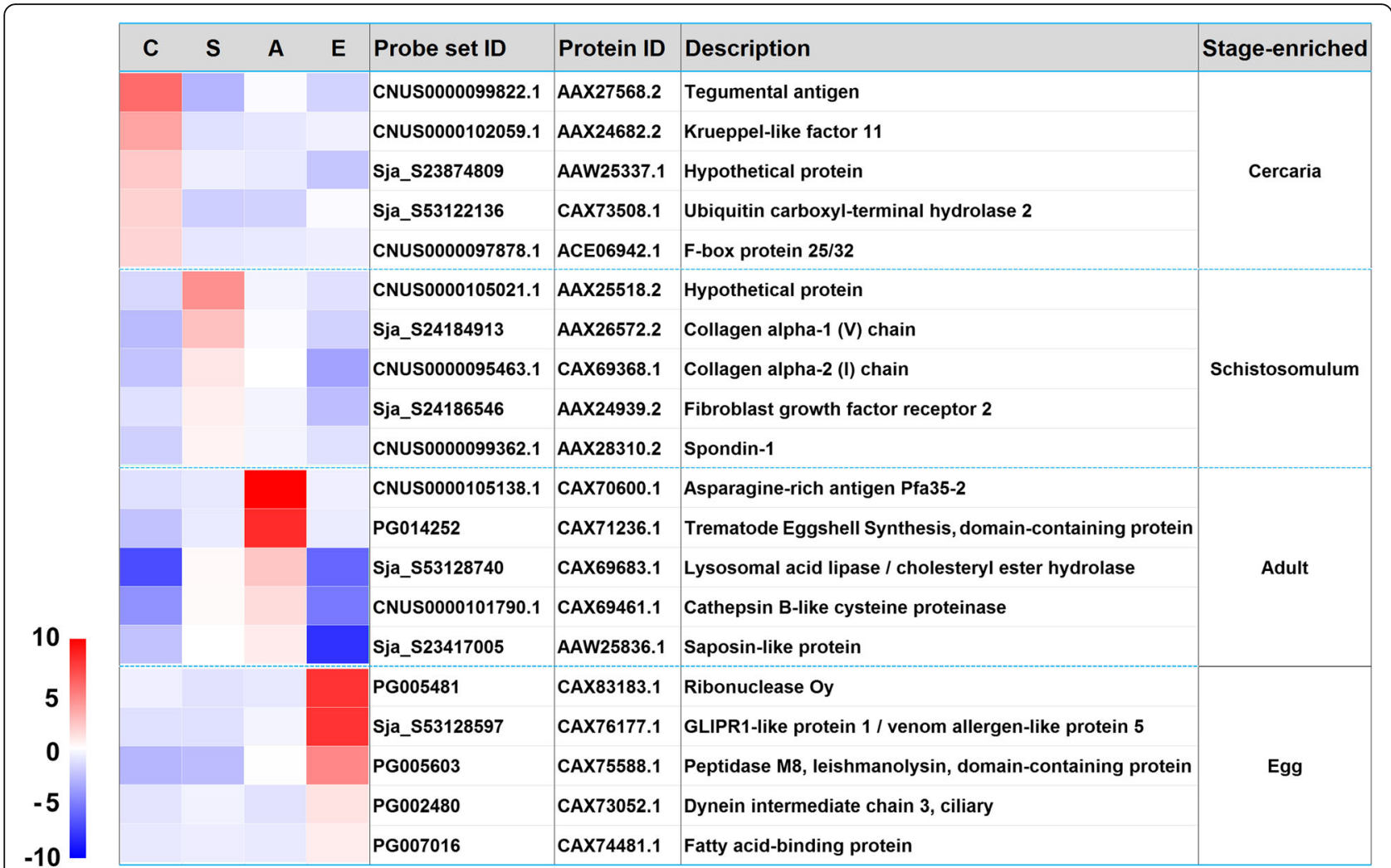

Fig. 3 Twenty stage-enriched genes selected for qPCR validation. The heat map illustrates the hierarchical clustering of 20 stage-enriched genes based on the transformed data of $\log _{2}$ FC value of the three biological replicates. Abbreviations: $C$, cercariae; $S$, hepatic schistosomula; A, adult worms; E, eggs

activity [61]. It has been shown previously that VAL-5 is mainly present in the egg, miracidium and sporocyst developmental stages [62].

\section{Genes enriched in cercariae}

Interestingly, a group of genes encoding transcription factors, i.e. homeobox protein SMOX-1 (AY915497), bhlhzip transcription factor max/bigmax (FN314500), pre-B-cell leukemia transcription factor 2 (AY809282), transcription factor 25 (AY808969), 20 (AY813668), BTF3 (EZ000130), TFIID subunit 3 (AY812404) and 7 (FN317813), IIIB subunit (AY812330), LIM/homeobox protein (AY915618) and transcriptional repressor NFX1(AY813973) were actively transcribed in cercariae (Additional file 4: Table S3), indicating gene transcription may not be as silent as previously suggested in this stage. It has been shown that the highest ratio of miRNAs, the critical post-transcriptional regulators, in the total small RNA population was observed in cercariae compared with other different developmental stages of S. japonicum [32, 63], leading us to hypothesise that a specific group of genes may be actively transcribed in this aquatic stage. In addition, miRNAs may inhibit the translation of a subset of these transcripts, forming a repertoire of genes that make schistosomula ready to adapt to subsequent intra-mammalian life. Further, there is epigenetic control of gene expression in $S$. mansoni cercariae [64]. Overall, these observations indicate that active transcriptional regulation occurs at different layers in cercariae to subtly control gene expression in this stage.

We also observed that an extensive gene panel involved in cellular signalling transduction, i.e. F-box protein 25/32 (EZ000162), dual specificity mitogenactivated protein kinase 2 (AY815572), Serine/threonine kinase NLK (FN317434), Rho GTPase-activating protein 39 (FN317833), GDP/GTP exchange factor Sec2p domain containing protein (FN317362), Rhoassociated protein kinase 1 (FN330915), mitogen-activated protein kinase 3 (EZ000180), Ran binding protein 9-related protein (AY812647), GTP-binding protein 2 (FN317377), NF-kappa-B inhibitor-interacting Ras-like protein 1 (AY812481), son of sevenless (AY915633), MAP kinase (AY594257), C-Jun-amino-terminal kinase-interacting protein 4 (AY808598), and regulator of G-protein signaling 7 (AY810841), were over-expressed in cercariae (Additional file 4: Table S3). These results support recent finding that three signaling pathways, extracellular signal-regulated 


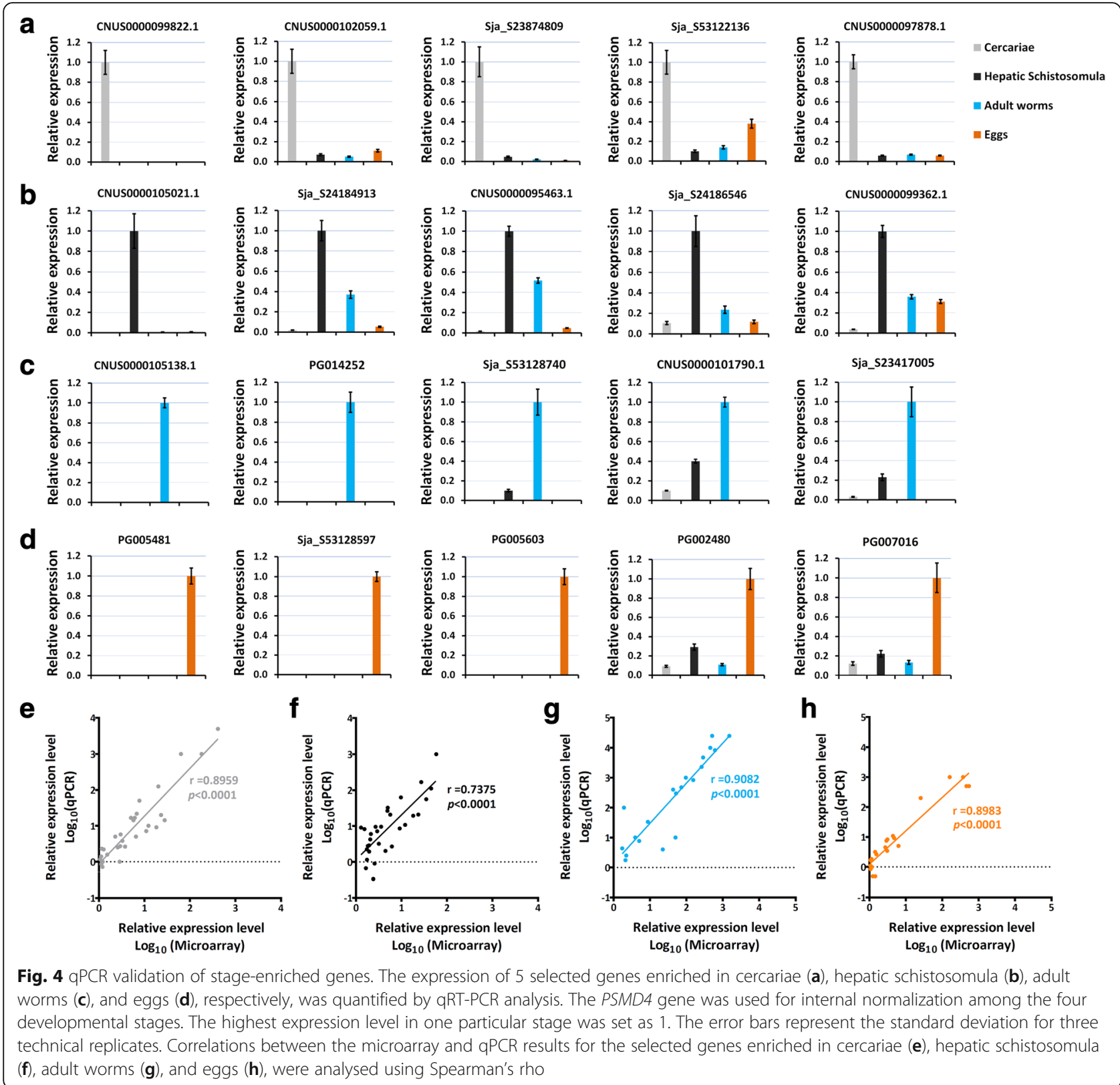

kinase (ERK), p38 mitogen-activated protein kinase (MAPK), and protein kinase C (PKC), are modulated in cercariae in response to light and temperature cues as well as the skin fatty acid linoleic acid (LA) and are important in host penetration mechanisms [65].

In line with, and expanding on, previous transcriptional studies on schistosomes [13, 14, 66], genes encoding an array of cytoskeleton motor proteins, including dynein light intermediate chain 1, cytosolic (AY809199), troponins (FN317001 and AY809606), tensin-1 (AY809674), villin (AY808977), myosin light chain kinase, actin-related protein 5 (FN326677), dynamin (AY809889), catenin beta (AY814842), coronin (AY814365), dynein light chain
Tctex-type 1 (AY811669) and alpha-actinin (FN326862) (Additional file 4: Table S3) were more highly expressed in cercariae than the other stages evaluated. Transcripts encoding LIM or PDZ domain-containing proteins, which contribute to cytoskeletal organisation, such as LIM/ homeobox protein (AY915618), actin binding LIM protein 1 (AY813306), four and a half LIM domains protein 2 (FN317368), and PDZ and LIM domain protein 7 (FN317962) (Additional file 4: Table S3), were also enriched in cercariae. Proteomic studies also revealed that cytoskeleton-related proteins are abundant in schistosome cercariae [67]. Together, these data indicate modulated signalling and motor activities and rigid transcriptional 


\section{a}

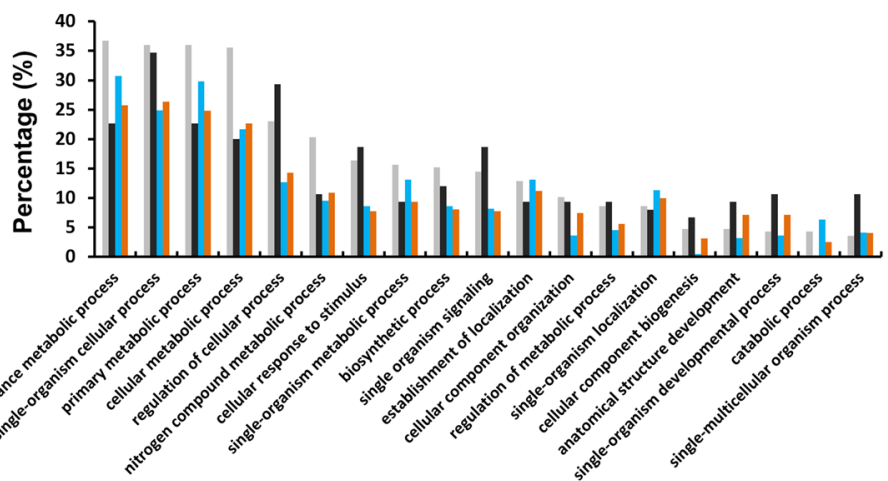

b Molecular function
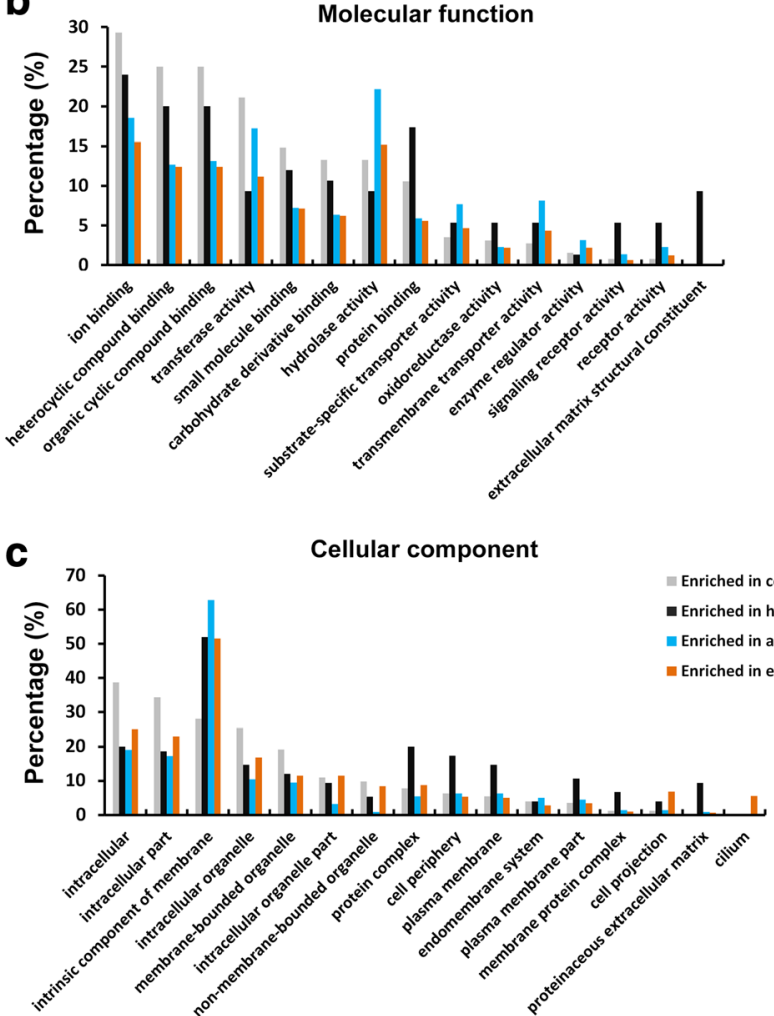

Fig. $5 \mathrm{GO}$ analysis of mRNA transcripts enriched in the four developmental stages of S. japonicum. The Blast2Go program defined the GO terms into three categories: biological processes (a), molecular functions (b) and cellular component (c). The $y$-axis shows the ratio of the number of mapped genes versus total number of genes in each cognate stage identified as a function of all available GO terms. The x-axis shows GO terms at the 3 rd level

regulation are the most important biological events in cercariae, which enable them to seek, invade and adapt to a suitable definitive host.

\section{Genes enriched in hepatic schistosomula}

On invading a mammalian host, schistosomes have evolved several mechanisms to adapt to, and survive in, the hostile host environment; in particular, they develop a unique syncytial tegument, as well as mechanisms of antigenic mimicry [33], immune modulation [68] and evasion $[69,70]$. In this study, we found extracellular matrix constituents, that are located in the tegumental protein assemblage, were enriched in hepatic schistosomula. These collagen components included, for example, collagen alpha-1(V) chain (AY810683, AY811988, and AY815998), alpha-1(IV) chain (AY809845), alpha-1(XXIV) chain (AY814344), alpha-2(I) chain (AY810097, FN313634) and alpha-2(V) chain (AY813923) (Additional file 5: Table S4). This observation raises the possibility that collagen components may form a protective barrier on 
Table 1 The top 25 genes enriched in S. japonicum cercariae, hepatic schistosomula, mixed adult worms and eggs

\begin{tabular}{|c|c|c|c|}
\hline NCBI Nucleotide & NCBI Protein & Annotation & FC \\
\hline \multicolumn{4}{|c|}{ Enriched in cercariae } \\
\hline AY811679.1 & AAX27568.2 & Tegumental antigen & 94.004 \\
\hline AY812964.1 & AAW24696.1 & Lysophosphatidic acid phosphatase type 6 & 89.015 \\
\hline AY808793.1 & AAX24682.2 & Krueppel-like factor 11 & 20.463 \\
\hline AY814888.1 & AAP06195.1 & Hypothetical protein & 20.323 \\
\hline AY915869.1 & AAX31090.1 & UPF0506 domain containing protein & 15.144 \\
\hline AY811006.1 & AAX26895.2 & Putative sodium-dependent transporter & 14.884 \\
\hline FN319257.1 & CAX74986.1 & Ribosomal protein 56 kinase beta-2 & 13.668 \\
\hline AY813254.1 & CAX83692.1 & Gag-Pol polyprotein & 11.090 \\
\hline AY812158.1 & AAX28047.2 & Calcium-dependent secretion activator & 10.898 \\
\hline FN327240.1 & CAX82964.1 & UPF0364 protein & 10.005 \\
\hline FN319112.1 & CAX74840.1 & Anti-inflammatory protein 16 & 9.750 \\
\hline AY809199.1 & AAX25088.2 & Dynein light intermediate chain 1 cytosolic & 9.060 \\
\hline AY815066.1 & AAW26798.1 & Calpain & 8.200 \\
\hline FN314407.1 & CAX70140.1 & Rab-protein 11 & 8.118 \\
\hline AY813232.1 & AAW24964.1 & DM9 domain-containing protein & 7.327 \\
\hline AY915497.1 & AAX30718.2 & Homeobox protein SMOX-1 & 7.320 \\
\hline AY813605 & AAW25337.1 & Hypothetical protein & 7.234 \\
\hline FN319705.1 & CAX75429.1 & THO complex subunit 1 & 6.827 \\
\hline AY813585.1 & AAW25317.1 & Hypothetical protein & 6.756 \\
\hline AY811834.1 & AAX27723.2 & AMP deaminase & 6.524 \\
\hline AY813088.1 & AAW24820.1 & Hypothetical protein & 6.357 \\
\hline FN314484 & CAX70217.1 & Hypothetical protein & 6.196 \\
\hline AY811464.1 & ABA40369.1 & 5'-AMP-activated protein kinase subunit gamma-1 & 6.165 \\
\hline EU046089.1 & AAW25910.1 & Cercarial stage-specific protein Sj2OH8 & 6.075 \\
\hline AY808884.1 & AF129816_1 & Retinoid $X$ receptor $\mathrm{RXR}-2$ & 6.011 \\
\hline \multicolumn{4}{|c|}{ Enriched in hepatic schistosomula } \\
\hline AY809629.1 & AAX25518.2 & Hypothetical protein & 33.897 \\
\hline AY810683 & AAX26572.2 & Putative collagen alpha-1(V) chain precursor & 9.200 \\
\hline AY815366.1 & AAW27592.1 & Alpha-ketoglutarate-dependent dioxygenase alkB 6 & 6.931 \\
\hline AY813429.1 & AAW25161.1 & Hypothetical protein & 5.290 \\
\hline AY810949.1 & AAX26838.2 & Homeobox protein engrailed-like SMOX-2 & 5.057 \\
\hline EZ000055.1 & ACE06835.1 & Vacuolar protein sorting-associated protein 29 & 5.021 \\
\hline AY810397.1 & AAX26286.2 & Protocadherin Fat 4 & 4.839 \\
\hline AY811075.1 & AAX26964.2 & Hypothetical protein & 4.831 \\
\hline AY815532.1 & AAW27264.1 & Hypothetical protein & 4.727 \\
\hline AY814356 & AAW26088.1 & RhoGAP domain containing protein & 4.610 \\
\hline AY811025.1 & AAX26914.2 & Serine/threonine-protein kinase Sgk1 & 4.342 \\
\hline AY809477.1 & AAX25366.2 & SAM and SH3 domain-containing protein 1 & 4.248 \\
\hline FN314446.1 & CAX70179.1 & Annexin A3 (Annexin III) & 4.037 \\
\hline AY814048.1 & AAW25780.1 & Basic proline-rich protein-like isoform & 3.967 \\
\hline AY808501.1 & AAR28090.2 & Nuclear receptor subfamily 4 group A & 3.956 \\
\hline AY809584.1 & AAX25473.2 & Hypothetical protein & 3.894 \\
\hline AY812287.1 & AAX28176.2 & Run domain Beclin-1 interacting and cysteine-rich containing protein & 3.806 \\
\hline
\end{tabular}


Table 1 The top 25 genes enriched in S. japonicum cercariae, hepatic schistosomula, mixed adult worms and eggs (Continued)

\begin{tabular}{|c|c|c|c|}
\hline AY813648.1 & AAW25380.1 & Hypothetical protein & 3.439 \\
\hline AY915540.1 & ABA40872.1 & Leishmanolysin-like peptidase & 3.419 \\
\hline AY812557.1 & AAX28446.2 & Aromatic-L-amino-acid decarboxylase & 3.335 \\
\hline AY808377.1 & AAX24266.2 & Regulator of G-protein signaling 3 & 3.250 \\
\hline FN313634.1 & CAX69368.1 & Collagen alpha-2(I) chain & 3.244 \\
\hline AY813683.1 & AAW25415.1 & Delphilin & 3.240 \\
\hline AY812144.1 & AAX28033.2 & Hypothetical protein & 3.212 \\
\hline AY813563 & AAW25295.1 & Hypothetical protein & 3.203 \\
\hline \multicolumn{4}{|c|}{ Enriched in mixed adult worms } \\
\hline FN314868.1 & CAX70600.1 & Asparagine-rich antigen Pfa35-2 & 1651.245 \\
\hline EZ000096 & ACE06876.1 & Putative eggshell protein precursor & 934.084 \\
\hline FN314999 & CAX70731.1 & TES domain containing protein & 704.455 \\
\hline AY813556.1 & AAW25288.1 & Hypothetical protein & 692.180 \\
\hline AY814029 & AAW25761.2 & Stress protein DDR48 (DNA damage-responsive protein 48 ) & 678.514 \\
\hline FN313935.1 & CAX69669.1 & Stress protein DDR48 (DNA damage-responsive protein 48 ) & 665.581 \\
\hline FN317103 & CAX72834.1 & Stress protein DDR48 (DNA damage-responsive protein 48 ) & 645.627 \\
\hline FN313912 & CAX69646.1 & TES domain containing protein & 604.574 \\
\hline FN313715.1 & CAX69449.1 & TES domain containing protein & 561.444 \\
\hline AY812810.1 & AAW24542.1 & Histidine-rich glycoprotein precursor & 526.698 \\
\hline FN315504.1 & CAX71236.1 & TES domain containing protein & 517.929 \\
\hline AY815518 & AAW27250.1 & TES domain containing protein & 489.519 \\
\hline FN314997 & CAX70729.1 & TES domain containing protein & 422.784 \\
\hline AY813405 & AAW25137.1 & TES domain containing protein & 407.588 \\
\hline AY815264.1 & AAW26996.1 & Tyrosinase 1 & 346.094 \\
\hline AY812315.1 & AAX28204.2 & Hypothetical protein & 330.410 \\
\hline FN330801 & CAX83018.1 & Stress protein DDR48 (DNA damage-responsive protein 48 ) & 235.455 \\
\hline AY814142.1 & AAW25874.1 & Putative FAM75 family member & 224.325 \\
\hline AY812904 & AAW24636.1 & Tyrosinase 2 & 209.523 \\
\hline FN315510.1 & CAX71242.1 & Hypothetical protein & 164.941 \\
\hline AY814814 & AAW26546.1 & Cadherin & 145.264 \\
\hline AY815418 & AAW27150.1 & Female-specific protein 800 & 135.097 \\
\hline FN316955 & CAX72686.1 & Prostatic spermine-binding protein precursor & 132.448 \\
\hline AY222885 & AAP05897.1 & Stress protein DDR48 (DNA damage-responsive protein 48) & 127.238 \\
\hline FN314903.1 & CAX70635.1 & Hypothetical protein & 107.908 \\
\hline \multicolumn{4}{|c|}{ Enriched in eggs } \\
\hline FN317800 & CAX73529.1 & Glutenin high molecular weight subunit DX5 & 1794.846 \\
\hline FN319280 & CAX75008.1 & Tetraspanin 22 & 1769.270 \\
\hline FN322023.1 & CAX77751.1 & Histidine-rich glycoprotein & 1656.913 \\
\hline FN324495.1 & CAX80219.1 & Hypothetical protein & 1549.720 \\
\hline FN326817 & CAX82541.1 & Histidine-rich glycoprotein & 1523.735 \\
\hline FN317759.1 & CAX73488.1 & Similar to venom allergen-like (VAL) 25 protein & 1062.695 \\
\hline FN324480.1 & CAX80126.1 & Hypothetical protein & 938.553 \\
\hline FN321785 & CAX77509.1 & Ribonuclease T2 & 850.487 \\
\hline FN321171.1 & CAX76897.1 & Hypothetical protein & 831.194 \\
\hline FN324498.1 & CAX80222.1 & Hypothetical protein & 776.801 \\
\hline
\end{tabular}


Table 1 The top 25 genes enriched in S. japonicum cercariae, hepatic schistosomula, mixed adult worms and eggs (Continued)

\begin{tabular}{llll}
\hline FN319117.1 & CAX74843.1 & ClA30 domain containing protein & 665.147 \\
FN317754 & CAX73483.1 & Tetraspanin & 663.055 \\
FN322724.1 & CAX78439.1 & Peptidase inhibitor 16 & 651.579 \\
FN319142 & CAX74870.1 & Hypothetical protein & 628.202 \\
FN320551 & CAX76277.1 & Egg protein CP1531 & 592.491 \\
FN326664 & CAX82388.1 & Hypothetical protein & 577.505 \\
AY816014.1 & AAW27746.1 & Ribonuclease S-4 & 534.668 \\
FN321764.1 & CAX77484.1 & Cell wall integrity and stress response component 1 & 488.342 \\
FN326758 & CAX82480.1 & Hypothetical protein & 484.608 \\
FN317167 & CAX72898.1 & Hypothetical protein & 481.352 \\
FN319216.1 & CAX74944.1 & Hypothetical protein & 453.890 \\
FN320451 & CAX76177.1 & GLIPR1-like protein 1/venom allergen-like protein 5 & 422.820 \\
FN317231 & CAX72962.1 & GLIPR1-like protein 1/venom allergen-like protein 5 & 417.438 \\
FN326877 & CAX82601.1 & Hypothetical protein & 416.455 \\
FN330952.1 & CAX83183.1 & Ribonuclease Oy & 414.347 \\
\hline
\end{tabular}

the worm surface, which may help the schistosomula evade host attack.

Schistosomula undertake a lengthy migration in the mammalian host to the portal venous system, where they mature into adult worms and pair. This migration is closely associated with locomotion activity controlled by the neuronal system. The data presented here show that neuronal activities may be particularly active in hepatic schistosomula, which could be linked to the fact that responses to environmental cues from the host and the subsequent control of mobility are required to guarantee that they reach their destination [22]. A cohort of genes involved in neuronal activities in this stage includes netrin receptor unc5B (AY915275), nephrin (AY809045), caskin 2 (AY812623), spondin-1 (AY812421), as well as the previously described genes protocadherin FAT4, aromatic-L-amino-acid decarboxylase and delphilin. Although the precise functions of these genes in schistosomes remain unknown, there is evidence from other studies that at least three are involved in axon guidance. In mammals, it has been shown that the unc $5 \mathrm{~B}$ receptor, interacting with netrin-1, activates the downstream signal transduction pathway that mediates axon guidance [71]. A caskin ortholog in Drosophila is a cytoplasmic adaptor protein, which has been shown to mediate Lar signal transduction motor axon guidance [72]. Similarly, spondin-1 is an extracellular matrix protein, and previous research showed that its $C$. elegans ortholog functions in axon guidance and fasciculation in motoneurons [73]. Also, the expression of nephrin homologues has been observed in the central nervous system of mammals, and nephrin may potentially interact with glutamate receptors [74, 75].
In multicellular organisms, apoptosis is a highly controlled cellular process of programmed cell death which plays a key role in maintaining cell populations during an organism's life-cycle. The apoptosis pathway has been suggested as a potential intervention target in schistosomes [76]. The activities of two central proteolytic enzymes involved in the apoptosis process, caspase- 3 and -7 , were shown to peak in $S$. japonicum schistosomula (14 days p.i.) [77]. The upregulated expression of caspase 7 (AY813428) in hepatic schistosomula was confirmed in this study (Additional file 5: Table S4). It is of note that a cohort of planarian neoblast-like cells with self-renewal function has been identified in S. mansoni, with a potential role in renewal of the tegument [78]. In this respect, fibroblast growth factor receptor 2, a crucial gene for the maintenance of neoblast-like cell population in schistosomes [79], was enriched in hepatic schistosomula (Additional file 5: Table S4), emphasising the requirement for rapid tegumental renewal during this period of fast-growth.

\section{Genes enriched in adult worms}

One of the major biological roles of adult worms is to produce a large number of eggs, a key process in the schistosome life-cycle. As earlier mentioned, within the top 25 adult-enriched genes, most are associated with egg production. However, two pre-requisites for egg production are mating and nutrient acquisition. In fulfilment of the former process, the gene encoding gynecophoral canal protein has been shown upregulated in adults, with a dramatic bias towards male worms [59]. In regards to nutrient uptake, and consistent with a previous study [18], over-expression of a number of 'blood processing' 
proteases in adult worms was also revealed here. For instance, cathepsin family members, i.e. cathepsin C (FN315267), cathepsin D2-like (AY812817), cathepsin Blike (AY814095), cathepsin L (FN313884) and cathepsin L-like isoforms (AY222874, FN314782, and FN314778), and aminopeptidase N (FN317672) were readily identified as adult worm-enriched genes (Additional file 6: Table S5). In addition, saposin B domain-containing proteins (FN314931, FN315898 and FN314355), which have been proposed as being involved in nutrient acquisition by disrupting the membrane of red blood cells to release haemoglobin [80], were highly expressed in adult worms.

In schistosomes, glycosylation is a complex process which plays a crucial role in their biology, particularly in terms of immune modulation [81]. A subset of transcripts involved glycosylation in was enriched in adult worms of $S$. japonicum. These genes included beta1,4-galactosyltransferase 4 (AY813412), glycosyltransferase 1 domain-containing protein 1 (FN319898), GDP-fucose protein O-fucosyltransferase 2 (AY810860), beta-1,3-galactosyltransferase 5 (AY814132), glycoprotein$\mathrm{N}$-acetylgalactosamine 3-beta-galactosyltransferase 1 (AY809881), glycoprotein 3-alpha-L-fucosyltransferase A (FN317387), alpha-1,3-mannosyl-glycoprotein 2-beta$\mathrm{N}$-acetylglucosaminyltransferase (AY812621), and alphaL-fucosidase-like protein (FN317475) (Additional file 6: Table S5). However, given the inherent complexity of glycosylation and that multiple glycosyltransferases responsible for similar molecular functions are present in the Schistosoma genomes [81, 82], it is difficult to conclude that the global level of glycosylation or the expression of specific glycans is higher in adults than in the other stages examined here.

\section{Genes enriched in eggs}

Globally, genes associated with the egg stage are involved in a diversity of biological functions, which may be the result of using samples for analysis that comprise a mixture of immature and mature eggs. In addition to anticipated genes encoding egg proteins, immunogenic miracidial antigens and major egg antigens, a number of genes involved in the cell cycle and proliferation, including meiosis expressed protein 1 (FN317540), meiosis-specific nuclear structural protein 1 (AY810474), mitogen-activated protein kinase 15 (FN317209), putative chromosome segregation protein SMC (AY812773), different isoforms of leishmanolysin-like peptidase (AY811259, FN317512, AY810562 and FN319863) and probably protein VHS3 (FN330961), placenta-specific gene 8 protein (FN317134), placental protein 25 homolog (FN317187) and centrosomal protein of $162 \mathrm{kDa}$ (AY810094), were upregulated in eggs (Additional file 7: Table S6). These transcripts may be enriched in immature eggs, hinting that active cell division is essential for embryonic development.

Further, a group of transcripts encoding tubulin and microtubule-associated motor proteins, i.e. tubulin alpha (FN317215), tubulin beta (FN320386), tubulin beta-2C chain (FN320061), cytoplasmic dynein light chain 1 (FN317588) and 2 (AY914882), dynein light chain 1, axonemal (FN317727), inner dynein arm light chain, axonemal (FN317915), outer dynein arm protein 1 (AY813443), dynein heavy chain 5, axonemal (AY810177), as well as the ciliary and flagellar microtubule components, i.e. tektins (AY814061, AY914954, FN317819 and FN314465), dynein intermediate chain 3 (AY810742) and outer dense fibre protein 3-B (FN318315) were over-expressed in eggs (Additional file 7: Table S6). These transcriptional differences may reflect the fact that a miracidium is enclosed in the eggshell of the mature egg, and once the egg is released into the external environment and contacts freshwater, a high level of movement is required for the larva to hatch and escape from the eggs [83], and to seek the snail intermediate host in order to establish an infection.

Though the miracidium is enclosed by an eggshell, an active parasite-host interplay takes place via pores in the egg [83]. On one hand, nutrients (e.g. iron, amino acid and lipid) are acquired by eggs from the host, a process supported by the upregulation of genes involved in transport and exchange activities, such as putative sodium-dependent transporter (FN318875), sodium/hydrogen exchanger (AY815720), sodium/calcium exchanger (FN318247), large neutral amino acids transporter small subunit 2 (FN327074), $\mathrm{Y}+\mathrm{L}$ amino acid transporter 2 (FN313722), high-affinity choline transporter 1 (FN317430), iron channels (i.e. voltage-gated hydrogen channel (FN318209), two pore calcium channel protein 2 (FN326741), and TWiK family of potassium channels protein (AY813707), and lipid metabolism (i.e. fatty acid-binding protein (FN318753) (Additional file 7: Table S6). On the other hand, it has been shown that major egg products from $S$. mansoni such as ribonuclease omega-1, kappa 5 (FN329842) and IPSE/alpha-1 are released into host tissues and modulate host immune responses [84-87]. In this study, S. japonicum homologues of ribonuclease omega-1 (FN330952) and kappa 5 (FN321248) were also enriched in the egg stage, although as yet, no homologue of IPSE/alpha-1 has been identified in this schistosome species.

\section{Conclusions}

In this study, we present the most comprehensive transcriptomic profile to date of four stage-associated genes in S. japonicum based on a next-generation DNA chip. The study has revealed the key biological and physiological features of the four development stages: cercariae, 
hepatic schistosomula, adult parasites and eggs. Overall, this study adds new insights on the developmental biology of S. japonicum which further the discovery of novel intervention targets against this persistent parasite and the disease it causes.

\section{Additional files}

Additional file 1: Figure S1. Denaturing agarose gel electrophoresis of RNA samples isolated from different developmental stages (1, cercariae; 2 , hepatic schistosomula; 3, adult worms; 4, eggs); one of three biological replicates for each stage are presented. (TIF $82 \mathrm{~kb}$ )

Additional file 2: Table S1. List of primer pairs used for $\mathrm{QPCR}$ validation. (XLSX $10 \mathrm{~kb}$ )

Additional file 3: Table S2. Retrieval of S. japonicum stage-enriched genes from the NCBI database based on the DNA chip results. (XLSX $9 \mathrm{~kb}$ )

Additional file 4: Table S3. Information on mRNA transcripts enriched in cercariae (forward probe). (XLSX $188 \mathrm{~kb}$ )

Additional file 5: Table S4. Information on mRNA transcripts enriched in hepatic schistosomula (forward probe). (XLSX $64 \mathrm{~kb}$ )

Additional file 6: Table S5. Information on mRNA transcripts enriched in mixed adult worms (forward probe). (XLSX $150 \mathrm{~kb}$ )

Additional file 7: Table S6. Information on mRNA transcripts enriched in eggs (forward probe). (XLSX $287 \mathrm{~kb}$ )

Additional file 8: Table S7. Information on EST transcripts enriched in cercariae (forward probe). (XLSX $81 \mathrm{~kb}$ )

Additional file 9: Table S8. Information on EST transcripts enriched in hepatic schistosomula (forward probe). (XLSX $25 \mathrm{~kb}$ )

Additional file 10: Table S9. Information on EST transcripts enriched in mixed adult worms (forward probe). (XLSX $51 \mathrm{~kb}$ )

Additional file 11: Table S10. Information on EST transcripts enriched in eggs (forward probe). (XLSX $51 \mathrm{~kb}$ )

Additional file 12: Figure S2. Heatmap for EST transcripts enriched in cercariae, hepatic schistosomula, adult worms and eggs. The heatmap was created by Heml 1.0 based on the transformed data of $\log _{2}$ FC value. The data are based on the mean of weighted signal intensity value of forward probe sets (three biological replicates). (TIF $110 \mathrm{~kb}$ )

Additional file 13: Table S11. Detailed $\mathrm{GO}$ annotation for mRNA transcripts enriched in cercariae. (XLSX $26 \mathrm{~kb}$ )

Additional file 14: Table S12. Detailed GO annotation for mRNA transcripts enriched in hepatic schistosomula. (XLSX $18 \mathrm{~kb}$ )

Additional file 15: Table S13. Detailed GO annotation for mRNA transcripts enriched in mixed adult worms. (XLSX $22 \mathrm{~kb}$ )

Additional file 16: Table S14. Detailed GO annotation for mRNA transcripts enriched in eggs. (XLSX $24 \mathrm{~kb}$ )

\section{Abbreviations}

CDS: Coding DNA sequences; DALYs: Disability adjusted life years; DGE: Digital gene expression; ERK: Extracellular signal-regulated kinase; ESTs: Expressed sequence tags; FC: Fold-changes; LAPs: Hydrolysis of lysophosphatidic acids; MAPK: Mitogen-activated protein kinase; PKC: Protein kinase C; SAGE: Serial analysis of gene expression; TES: Trematode eggshell synthesis;

UTRS: Untranslated regions; VAL: Venom allergen-like

\section{Acknowledgements}

We thank the Chinese National Genome Center at Shanghai for making S. japonicum genome publicly available.

\section{Funding}

This study was supported by the National Natural Science Foundation of China (Grant No. 81270026), the National S \& T Major Program (Grant No. 2012ZX 10004-220), the Special Fund for Health Research in the Public Interest (Grant No. 201202019), and the Program for Changjiang Scholars and
Innovative Research Team in University (IRT13007). DPM is a NHMRC Senior Principal Research Fellow and Senior Scientist at QIMR Berghofer Medical Research Institute. The funders had no role in study design, data collection and analysis, decision to publish, or preparation of the manuscript.

\section{Availability of data and materials}

Raw data and the normalized data have been deposited at the public domain Gene Expression Omnibus under the accession number for the platform GPL18617 and series GSE57143.

\section{Authors' contributions}

PC and QC conceived the project and designed the strategy. PC, SL, XP and $\mathrm{NH}$ carried out the experiments. PC, SL, DPM and QC analysed the data. PC, $H Y, D P M$ and QC wrote the manuscript. All authors read and approved the final manuscript.

\section{Competing interests}

The authors declare that they have no competing interests.

\section{Consent for publication}

Not applicable.

\section{Ethics approval and consent to participate}

All procedures performed on animals within this study were conducted following animal husbandry guidelines of the Chinese Academy of Medical Sciences and with permission from the Experimental Animal Committee (Institute of Pathogen Biology, CAMS) with Ethical Clearance Number IPB2011-6.

\section{Author details}

'MOH Key Laboratory of Systems Biology of Pathogens, Institute of Pathogen Biology, Chinese Academy of Medical Sciences \& Peking Union Medical College, Beijing, People's Republic of China. ${ }^{2}$ Molecular Parasitology Laboratory, QIMR Berghofer Medical Research Institute, Queensland, Australia. ${ }^{3}$ Key Laboratory of Zoonosis, Shenyang Agriculture University, Shenyang, People's Republic of China.

Received: 5 November 2016 Accepted: 21 December 2016

Published online: 10 January 2017

\section{References}

1. Steinmann P, Keiser J, Bos R, Tanner M, Utzinger J. Schistosomiasis and water resources development: systematic review, meta-analysis, and estimates of people at risk. Lancet Infect Dis. 2006;6:411-25.

2. Weerakoon KG, Gobert GN, Cai P, McManus DP. Advances in the diagnosis of human schistosomiasis. Clin Microbiol Rev. 2015;28:939-67.

3. Hotez PJ, Alvarado M, Basanez MG, Bolliger I, Bourne R, Boussinesq M, et al. The global burden of disease study 2010: interpretation and implications for the neglected tropical diseases. PLoS Negl Trop Dis. 2014;8:e2865.

4. Mutapi F, Rujeni N, Bourke C, Mitchell K, Appleby L, Nausch N, et al. Schistosoma haematobium treatment in 1-5 year old children: safety and efficacy of the antihelminthic drug praziquantel. PLoS Negl Trop Dis. 2011;5:e1143.

5. Chen MG. Assessment of morbidity due to Schistosoma japonicum infection in China. Infect Dis Poverty. 2014;3:6.

6. Cai P, Gobert GN, You H, McManus DP. The Tao survivorship of schistosomes: implications for schistosomiasis control. Int J Parasitol. 2016:46:453-63.

7. Hu W, Yan Q, Shen DK, Liu F, Zhu ZD, Song HD, et al. Evolutionary and biomedical implications of a Schistosoma japonicum complementary DNA resource. Nat Genet. 2003;35:139-47.

8. Verjovski-Almeida S, DeMarco R, Martins EA, Guimaraes PE, Ojopi EP, Paquola AC, et al. Transcriptome analysis of the acoelomate human parasite Schistosoma mansoni. Nat Genet. 2003;35:148-57.

9. Berriman M, Haas BJ, LoVerde PT, Wilson RA, Dillon GP, Cerqueira GC, et al. The genome of the blood fluke Schistosoma mansoni. Nature. 2009:460: 352-8.

10. The Schistosoma japonicum Genome Sequencing and Functional Analysis Consortium. The Schistosoma japonicum genome reveals features of hostparasite interplay. Nature. 2009;460:345-51.

11. Young ND, Jex AR, Li B, Liu S, Yang L, Xiong Z, et al. Whole-genome sequence of Schistosoma haematobium. Nat Genet. 2012;44:221-5. 
12. Waisberg M, Lobo FP, Cerqueira GC, Passos LK, Carvalho OS, Franco GR, et al. Microarray analysis of gene expression induced by sexual contact in Schistosoma mansoni. BMC Genomics. 2007;8:181.

13. Jolly ER, Chin CS, Miller S, Bahgat MM, Lim KC, DeRisi J, et al. Gene expression patterns during adaptation of a helminth parasite to different environmental niches. Genome Biol. 2007:8:R65.

14. Gobert GN, Moertel L, Brindley PJ, McManus DP. Developmental gene expression profiles of the human pathogen Schistosoma japonicum. BMC Genomics. 2009;10:128.

15. Chai M, McManus DP, McInnes R, Moertel L, Tran M, Loukas A, et al. Transcriptome profiling of lung schistosomula, in vitro cultured schistosomula and adult Schistosoma japonicum. Cell Mol Life Sci. 2006;63:919-29.

16. Moertel L, McManus DP, Piva TJ, Young L, McInnes RL, Gobert GN. Oligonucleotide microarray analysis of strain- and gender-associated gene expression in the human blood fluke, Schistosoma japonicum. Mol Cell Probes. 2006;20:280-9.

17. Fitzpatrick JM, Johansen MV, Johnston DA, Dunne DW, Hoffmann KF. Gender-associated gene expression in two related strains of Schistosoma japonicum. Mol Biochem Parasitol. 2004;136:191-209.

18. Parker-Manuel SJ, Ivens AC, Dillon GP, Wilson RA. Gene expression patterns in larval Schistosoma mansoni associated with infection of the mammalian host. PLoS Negl Trop Dis. 2011;5:e1274.

19. Ojopi EP, Oliveira PS, Nunes DN, Paquola A, DeMarco R, Gregorio SP, et al. A quantitative view of the transcriptome of Schistosoma mansoni adultworms using SAGE. BMC Genomics. 2007;8:186.

20. Williams DL, Sayed AA, Bernier J, Birkeland SR, Cipriano MJ, Papa AR, et al. Profiling Schistosoma mansoni development using serial analysis of gene expression (SAGE). Exp Parasitol. 2007;117:246-58.

21. Cogswell AA, Kommer VP, Williams DL. Transcriptional analysis of a unique set of genes involved in Schistosoma mansoni female reproductive biology. PLoS Negl Trop Dis. 2012;6:e1907.

22. Piao X, Cai P, Liu S, Hou N, Hao L, Yang F, et al. Global expression analysis revealed novel gender-specific gene expression features in the blood fluke parasite Schistosoma japonicum. PLoS One. 2011;6:e18267.

23. Anderson L, Amaral MS, Beckedorff F, Silva LF, Dazzani B, Oliveira KC, et al. Schistosoma mansoni egg, adult male and female comparative gene expression analysis and identification of novel genes by RNA-Seq. PLoS Negl Trop Dis. 2015;9:e0004334

24. Picard MA, Boissier J, Roquis D, Grunau C, Allienne JF, Duval D, et al. Sex-biased transcriptome of Schistosoma mansoni: host-parasite interaction, genetic determinants and epigenetic regulators are associated with sexual differentiation. PLoS Negl Trop Dis. 2016;10:e0004930.

25. Jones MK, Higgins T, Stenzel DJ, Gobert GN. Towards tissue specific transcriptomics and expression pattern analysis in schistosomes using laser microdissection microscopy. Exp Parasitol. 2007;117:259-66.

26. Gobert GN, McManus DP, Nawaratna S, Moertel L, Mulvenna J, Jones MK. Tissue specific profiling of females of Schistosoma japonicum by integrated laser microdissection microscopy and microarray analysis. PLoS Negl Trop Dis. 2009;3:e469.

27. Nawaratna SS, McManus DP, Moertel L, Gobert GN, Jones MK. Gene Atlasing of digestive and reproductive tissues in Schistosoma mansoni. PLoS Negl Trop Dis. 2011;5:e1043.

28. Fitzpatrick JM, Peak E, Perally S, Chalmers IW, Barrett J, Yoshino TP, et al. Anti-schistosomal intervention targets identified by life-cycle transcriptomic analyses. PLoS Negl Trop Dis. 2009;3:e543.

29. Liu S, Cai P, Hou N, Piao X, Wang H, Hung T, et al. Genome-wide identification and characterization of a panel of house-keeping genes in Schistosoma japonicum. Mol Biochem Parasitol. 2012;182:75-82.

30. Liu S, Cai P, Piao X, Hou N, Zhou X, Wu C, et al. Expression profile of the Schistosoma japonicum degradome reveals differential protease expression patterns and potential anti-schistosomal intervention targets. PLoS Comput Biol. 2014;10:e1003856

31. Liu S, Zhou X, Piao X, Wu C, Hou N, Chen Q. Comparative analysis of transcriptional profiles of adult Schistosoma japonicum from different laboratory animals and the natural host, water buffalo. PLoS Negl Trop Dis. 2015;9:e0003993.

32. Cai P, Piao X, Hao L, Liu S, Hou N, Wang H, et al. A deep analysis of the small noncoding RNA population in Schistosoma japonicum eggs. PLoS One. 2013;8:e64003.

33. Wu C, Hou N, Piao X, Liu S, Cai P, Xiao Y, et al. Non-immune immunoglobulins shield Schistosoma japonicum from host immunorecognition. Sci Rep. 2015;5:13434
34. Li DD, Zhao LX, Mylonakis E, Hu GH, Zou Y, Huang TK, et al. In vitro and in vivo activities of pterostilbene against Candida albicans biofilms. Antimicrob Agents Chemother. 2014;58:2344-55.

35. Irizarry RA, Hobbs B, Collin F, Beazer-Barclay YD, Antonellis KJ, Scherf U, et al. Exploration, normalization, and summaries of high density oligonucleotide array probe level data. Biostatistics. 2003;4:249-64.

36. Irizarry RA, Bolstad BM, Collin F, Cope LM, Hobbs B, Speed TP. Summaries of Affymetrix GeneChip probe level data. Nucleic Acids Res. 2003;31:e15.

37. Deng W, Wang Y, Liu Z, Cheng H, Xue Y. Heml: a toolkit for illustrating heatmaps. PLoS One. 2014;9:e111988.

38. Gotz S, Garcia-Gomez JM, Terol J, Williams TD, Nagaraj SH, Nueda MJ, et al. High-throughput functional annotation and data mining with the Blast2GO suite. Nucleic Acids Res. 2008:36:3420-35.

39. Marchler-Bauer A, Derbyshire MK, Gonzales NR, Lu S, Chitsaz F, Geer LY, et al. CDD: NCBI's conserved domain database. Nucleic Acids Res. 2015:43: D222-6.

40. Cai P, Piao X, Hou N, Liu S, Wang H, Chen Q. Identification and characterization of argonaute protein, Ago2 and its associated small RNAs in Schistosoma japonicum. PLoS Negl Trop Dis. 2012;6:e1745.

41. Ashburner M, Ball CA, Blake JA, Botstein D, Butler H, Cherry JM, et al. Gene ontology: tool for the unification of biology. The Gene Ontology Consortium. Nat Genet. 2000;25:25-9.

42. Valovka T, Verdier F, Cramer R, Zhyvoloup A, Fenton T, Rebholz H, et al. Protein kinase $\mathrm{C}$ phosphorylates ribosomal protein $\mathrm{S} 6$ kinase betall and regulates its subcellular localization. Mol Cell Biol. 2003;23:852-63.

43. Daily NJ, Boswell KL, James DJ, Martin TF. Novel interactions of CAPS (Ca ${ }^{+}$-dependent activator protein for secretion) with the three neuronal SNARE proteins required for vesicle fusion. J Biol Chem. 2010;285:35320-9.

44. Ligasova A, Bulantova J, Sebesta O, Kasny M, Koberna K, Mikes L. Secretory glands in cercaria of the neuropathogenic schistosome Trichobilharzia regenti - ultrastructural characterization, 3-D modelling, volume and $\mathrm{pH}$ estimations. Parasit Vectors. 2011:4:162.

45. Morisaki T, Gross M, Morisaki H, Pongratz D, Zollner N, Holmes EW. Molecular basis of AMP deaminase deficiency in skeletal muscle. Proc Natl Acad Sci U S A. 1992;89:6457-61.

46. Neumann D, Woods A, Carling D, Wallimann T, Schlattner U. Mammalian AMP-activated protein kinase: functional, heterotrimeric complexes by coexpression of subunits in Escherichia coli. Protein Expr Purif. 2003:30:230-7.

47. Morgan R. Engrailed: complexity and economy of a multi-functional transcription factor. FEBS Lett. 2006:580:2531-3.

48. Webster PJ, Mansour TE. Conserved classes of homeodomains in Schistosoma mansoni, an early bilateral metazoan. Mech Dev. 1992;38:25-32.

49. Mansley MK, Watt GB, Francis SL, Walker DJ, Land SC, Bailey MA, et al. Dexamethasone and insulin activate serum and glucocorticoid-inducible kinase 1 (SGK1) via different molecular mechanisms in cortical collecting duct cells. Physiol Rep. 2016;4:e12792.

50. Wu W, LoVerde PT. Nuclear hormone receptors in parasitic helminths. Mol Cell Endocrinol. 2011;334:56-66.

51. Wu W, Loverde PT. Schistosoma mansoni: identification of SmNR4A, a member of nuclear receptor subfamily 4. Exp Parasitol. 2008;120:208-13.

52. Badouel C, Zander MA, Liscio N, Bagherie-Lachidan M, Sopko R, Coyaud E, et al. Fat1 interacts with Fat4 to regulate neural tube closure, neural progenitor proliferation and apical constriction during mouse brain development. Development. 2015;142:2781-91.

53. Brun L, Ngu LH, Keng WT, Ch'ng GS, Choy YS, Hwu WL, et al. Clinical and biochemical features of aromatic L-amino acid decarboxylase deficiency. Neurology. 2010;75:64-71.

54. Miyagi Y, Yamashita T, Fukaya M, Sonoda T, Okuno T, Yamada K, et al. Delphilin: a novel PDZ and formin homology domain-containing protein that synaptically colocalizes and interacts with glutamate receptor delta 2 subunit. J Neurosci. 2002;22:803-14.

55. Tararam CA, Farias LP, Wilson RA, Leite LC. Schistosoma mansoni Annexin 2: molecular characterization and immunolocalization. Exp Parasitol. 2010;126: $146-55$

56. Leow CY, Willis C, Osman A, Mason L, Simon A, Smith BJ, et al. Crystal structure and immunological properties of the first annexin from Schistosoma mansoni: insights into the structural integrity of the schistosomal tegument. FEBS J. 2014;281:1209-25.

57. Mao Y, Kuta A, Crespo-Enriquez I, Whiting D, Martin T, Mulvaney J, et al. Dchs1-Fat4 regulation of polarized cell behaviours during skeletal morphogenesis. Nat Commun. 2016;7:11469. 
58. Fuse A, Furuya N, Kakuta S, Inose A, Sato M, Koike M, et al. VPS29-VPS35 intermediate of retromer is stable and may be involved in the retromer complex assembly process. FEBS Lett. 2015;589:1430-6.

59. Cai P, Liu S, Piao X, Hou N, Gobert GN, McManus DP, et al. Comprehensive transcriptome analysis of sex-biased expressed genes reveals discrete biological and physiological features of male and female Schistosoma japonicum. PLoS Negl Trop Dis. 2016;10:e0004684.

60. Fitzpatrick JM, Hirai Y, Hirai H, Hoffmann KF. Schistosome egg production is dependent upon the activities of two developmentally regulated tyrosinases. FASEB J. 2007;21:823-35.

61. Ferguson BJ, Newland SA, Gibbs SE. Tourlomousis P, Fernandes dos Santos $P$, Patel MN, et al. The Schistosoma mansoni T2 ribonuclease omega-1 modulates inflammasome-dependent IL-1beta secretion in macrophages. Int J Parasitol. 2015;45:809-13.

62. Chalmers IW, McArdle AJ, Coulson RM, Wagner MA, Schmid R, Hirai H, et al. Developmentally regulated expression, alternative splicing and distinct subgroupings in members of the Schistosoma mansoni venom allergen-like (SmVAL) gene family. BMC Genomics. 2008;9:89.

63. Cai P, Hou N, Piao X, Liu S, Liu H, Yang F, et al. Profiles of small non-coding RNAs in Schistosoma japonicum during development. PLoS Negl Trop Dis. 2011;5:e1256.

64. Roquis D, Lepesant JM, Picard MA, Freitag M, Parrinello H, Groth M, et al. The epigenome of Schistosoma mansoni provides insight about how cercariae poise transcription until infection. PLoS Negl Trop Dis. 2015;9: e0003853.

65. Ressurreicao M, Kirk RS, Rollinson D, Emery AM, Page NM, Walker AJ. Sensory protein kinase signaling in Schistosoma mansoni cercariae: host location and invasion. J Infect Dis. 2015;212:1787-97.

66. Han ZG, Brindley PJ, Wang SY, Chen Z. Schistosoma genomics: new perspectives on schistosome biology and host-parasite interaction. Annu Rev Genomics Hum Genet. 2009;10:211-40.

67. Liu M, Ju C, Du XF, Shen HM, Wang JP, Li J, et al. Proteomic analysis on cercariae and schistosomula in reference to potential proteases involved in host invasion of Schistosoma japonicum larvae. J Proteome Res. 2015;14:4623-34.

68. Jenkins SJ, Hewitson JP, Jenkins GR, Mountford AP. Modulation of the host's immune response by schistosome larvae. Parasite Immunol. 2005;27:385-93.

69. Cai P, Bu L, Wang J, Wang Z, Zhong X, Wang H. Molecular characterization of Schistosoma japonicum tegument protein tetraspanin-2: sequence variation and possible implications for immune evasion. Biochem Biophys Res Commun. 2008;372:197-202.

70. Z Zhang W, Li J, Duke M, Jones MK, Kuang L, Zhang J, et al. Inconsistent protective efficacy and marked polymorphism limits the value of Schistosoma japonicum tetraspanin-2 as a vaccine target. PLoS Negl Trop Dis. 2011;5:e1166.

71. Bradford D, Cole SJ, Cooper HM. Netrin-1: diversity in development. Int J Biochem Cell Biol. 2009:41:487-93.

72. Weng YL, Liu N, DiAntonio A, Broihier HT. The cytoplasmic adaptor protein Caskin mediates Lar signal transduction during Drosophila motor axon guidance. J Neurosci. 2011;31:4421-33.

73. Woo WM, Berry EC, Hudson ML, Swale RE, Goncharov A, Chisholm AD The C. elegans F-spondin family protein SPON-1 maintains cell adhesion in neural and non-neural tissues. Development. 2008:135:2747-56.

74. Li M, Armelloni S, Ikehata M, Corbelli A, Pesaresi M, Calvaresi N, et al. Nephrin expression in adult rodent central nervous system and its interaction with glutamate receptors. J Pathol. 2011;225:118-28.

75. Putaala $\mathrm{H}$, Soininen $\mathrm{R}$, Kilpelainen $\mathrm{P}$, Wartiovaara J, Tryggvason $\mathrm{K}$. The murine nephrin gene is specifically expressed in kidney, brain and pancreas: inactivation of the gene leads to massive proteinuria and neonatal death. Hum Mol Genet. 2001;10:1-8.

76. Lee EF, Young ND, Lim NT, Gasser RB, Fairlie WD. Apoptosis in schistosomes: toward novel targets for the treatment of schistosomiasis. Trends Parasitol. 2014;30:75-84

77. Han H, Peng J, Gobert GN, Hong Y, Zhang M, Han Y, et al. Apoptosis phenomenon in the schistosomulum and adult worm life cycle stages of Schistosoma japonicum. Parasitol Int. 2013;62:100-8.

78. Pearson MS, Loukas A. The parasite's new clothes. Elife. 2016;5:e12473.

79. Collins 3rd JJ, Wang B, Lambrus BG, Tharp ME, lyer H, Newmark PA. Adult somatic stem cells in the human parasite Schistosoma mansoni. Nature. 2013;494:476-9.

80. Don TA, Bethony JM, Loukas A. Saposin-like proteins are expressed in the gastrodermis of Schistosoma mansoni and are immunogenic in natural infections. Int J Infect Dis. 2008;12:e39-47.
81. Mickum ML, Prasanphanich NS, Heimburg-Molinaro J, Leon KE, Cummings RD. Deciphering the glycogenome of schistosomes. Front Genet. 2014;5:262

82. Smit CH, van Diepen A, Nguyen DL, Wuhrer M, Hoffmann KF, Deelder AM, et al. Glycomic analysis of life stages of the human parasite Schistosoma mansoni reveals developmental expression profiles of functional and antigenic glycan motifs. Mol Cell Proteomics. 2015;14:1750-69.

83. Jones MK, Bong SH, Green KM, Holmes P, Duke M, Loukas A, et al. Correlative and dynamic imaging of the hatching biology of Schistosoma japonicum from eggs prepared by high pressure freezing. PLoS Negl Trop Dis. 2008;2:e334.

84. Steinfelder S, Andersen JF, Cannons JL, Feng CG, Joshi M, Dwyer D, et al. The major component in schistosome eggs responsible for conditioning dendritic cells for Th2 polarization is a T2 ribonuclease (omega-1). J Exp Med. 2009;206:1681-90.

85. Meyer NH, Mayerhofer $H_{1}$, Tripsianes $\mathrm{K}$, Blindow S, Barths D, Mewes A, et al. A Crystallin fold in the Interleukin-4-inducing principle of Schistosoma mansoni eggs (IPSE/alpha-1) mediates IgE binding for antigen-independent basophil activation. J Biol Chem. 2015;290:22111-26.

86. Schramm G, Mohrs K, Wodrich M, Doenhoff MJ, Pearce EJ, Haas H, et al. Cutting edge: IPSE/alpha-1, a glycoprotein from Schistosoma mansoni eggs, induces IgE-dependent, antigen-independent IL-4 production by murine basophils in vivo. J Immunol. 2007:178:6023-7.

87. Schramm G, Hamilton JV, Balog Cl, Wuhrer M, Gronow A, Beckmann S, et al. Molecular characterisation of kappa-5, a major antigenic glycoprotein from Schistosoma mansoni eggs. Mol Biochem Parasitol. 2009;166:4-14.

\section{Submit your next manuscript to BioMed Central and we will help you at every step:}

- We accept pre-submission inquiries

- Our selector tool helps you to find the most relevant journal

- We provide round the clock customer support

- Convenient online submission

- Thorough peer review

- Inclusion in PubMed and all major indexing services

- Maximum visibility for your research

Submit your manuscript at www.biomedcentral.com/submit
) Biomed Central 